\title{
Digital cholangioscopy-guided retrieval of a migrated hepaticogastrostomy stent through a created hepaticogastrostomy route
}

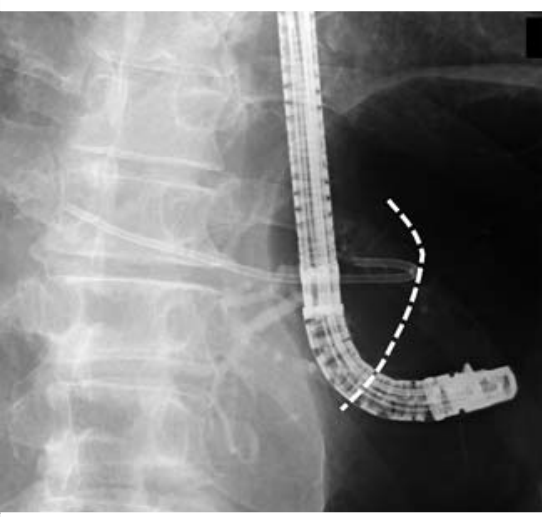

- Fig. 1 A migrated hepaticogastrostomy stent in the bile duct at segment 2 . The dotted line represents the gastric wall.

Endoscopic ultrasound-guided hepaticogastrostomy (EUS-HGS) is increasingly utilized for benign biliary diseases in cases with surgically altered anatomy $[1,2]$, but stent migration is a potential complication [3]. We describe successful retrieval of a migrated hepaticogastrostomy stent through a newly created EUS-HGS route using a digital cholangioscope.

A 71-year-old man with a history of extended right hepatectomy for cholangiocarcinoma was referred for treatment of intrahepatic biliary stones. As stone extraction under enteroscope-assisted endoscopic retrograde cholangiopancreatography at an outside hospital failed due to multiple intrahepatic stones, we decided to perform EUS-HGS.

After plastic stent placement in the bile duct at segment 2 , stone extraction was attempted through the fistula during the second session. Stone extraction was incomplete due to technical difficulty and large stone size, and therefore we planned to perform extracorporeal shock wave lithotripsy using a nasobiliary catheter. During nasobiliary catheter insertion following placement of a 7-Fr straighttype plastic stent as HGS, we discovered that the stent had migrated into the fistula tract due to interference between the
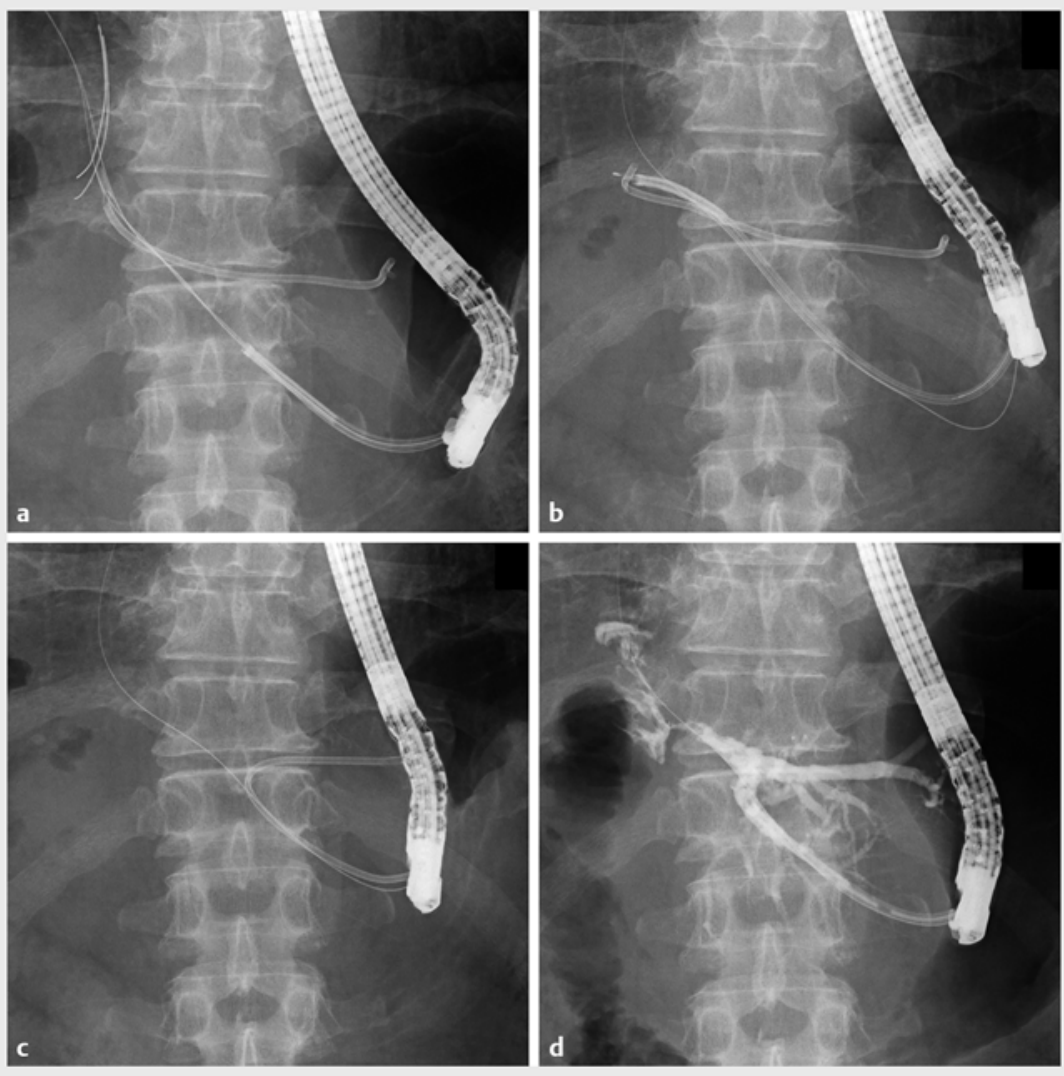

- Fig. 2 Retrieval of a migrated stent through a second hepaticogastrostomy fistula utilizing digital cholangioscopy. a The digital cholangioscope was advanced through a newly created hepaticogastrostomy fistula. b The migrated stent was grasped using a mini snare under digital cholangioscopic visualization. c The stent was successfully withdrawn to the stomach. d Fluoroscopic image of the biliary tree after removal of the stent and intrahepatic biliary stones.

two tubes ( $\mathbf{F i g} .1$ ). Although there was no risk of bile peritonitis thanks to the mature fistula, additional EUS-HGS in segment 3 was performed to prevent cholangitis. After fistula maturation, the fistula was dilated using a balloon catheter, and a digital cholangioscope (SpyGlass DS; Boston Scientific Japan, Tokyo, Japan) was inserted (\Fig. 2, \ Video 1). Under direct visualization, the migrated stent was readily grasped using a dedicated mini snare (SpySnare, Boston Scientific) and successfully retrieved. Finally, stones were extracted using electro- hydraulic lithotripsy under direct cholangioscopic visualization [4]. No procedure-related adverse event occurred.

Although stent dislocation can be a serious complication during interventional EUS and may need a surgical intervention, cholangioscopy-guided removal of a migrated stent through another route can be a nonsurgical salvage option, as we previously reported in EUS-guided pancreatic duct drainage [5].

Endoscopy_UCTN_Code_CPL_1AK_2AI 


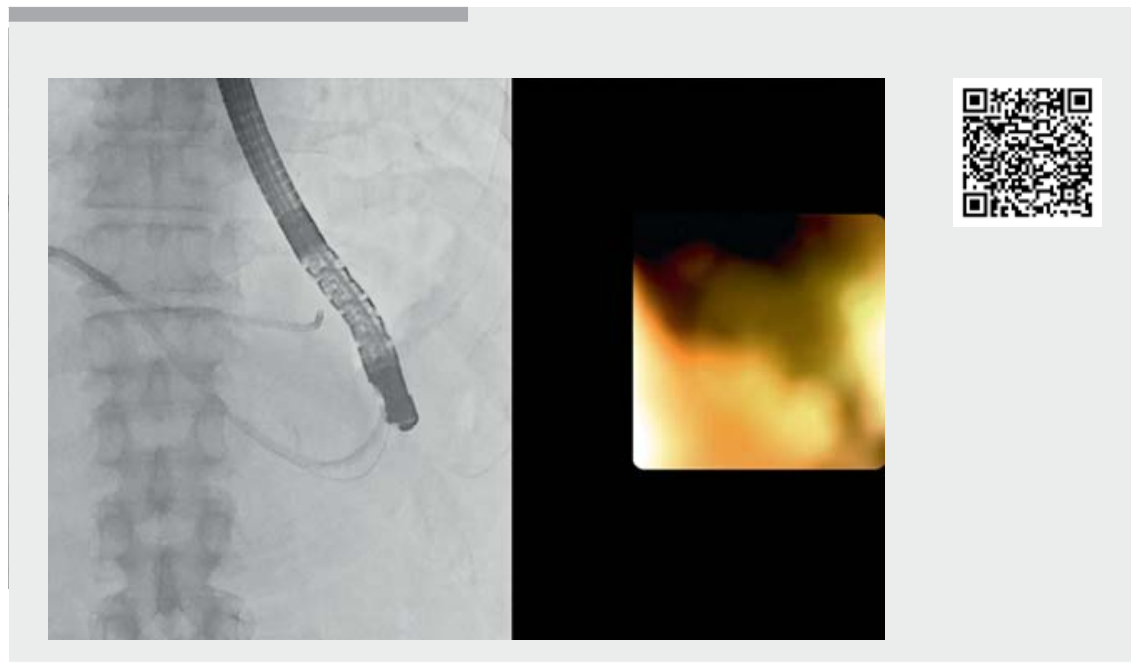

Video 1 Retrieval of a migrated stent through a second hepaticogastrostomy fistula utilizing digital cholangioscopy.

Competing interests

The authors declare that they have no conflict of interest.

\section{The authors}

Tomotaka Saito ${ }^{1}$, Tsuyoshi Hamada ${ }^{1}$, Hirofumi Kogure', Yousuke Nakai ${ }^{1,2}$, Kazuhiko Koike ${ }^{1}$

1 Department of Gastroenterology, Graduate School of Medicine, The University of Tokyo, Tokyo, Japan

2 Department of Endoscopy and Endoscopic Surgery, Graduate School of Medicine, The University of Tokyo, Tokyo, Japan

\section{Corresponding author}

\section{Yousuke Nakai, MD, PhD}

Department of Endoscopy and Endoscopic Surgery, Graduate School of Medicine, The University of Tokyo, 7-3-1 Hongo, Bunkyo-ku, Tokyo 113-8655, Japan Fax: +81-3-58009801 ynakai-tky@umin.ac.jp

\section{References}

[1] Mukai S, Itoi T, Sofuni A et al. EUS-guided antegrade intervention for benign biliary diseases in patients with surgically altered anatomy (with videos). Gastrointest Endosc 2019; 89: 399-407

[2] Nakai Y, Kogure H, Yamada A et al. Endoscopic management of bile duct stones in patients with surgically altered anatomy. Dig Endosc 2018; 30 (Suppl. 01): 67-74
[3] Fujisawa T, Saito H, Isayama H et al. Endoscopic removal of a metal stent that migrated into the peritoneal cavity after endoscopic ultrasound-guided hepaticogastrostomy. Dig Endosc 2019; 31: e74-e75

[4] Sato T, Nakai Y, Kogure H et al. Electrohydraulic lithotripsy through a fistula of EUSguided hepaticogastrostomy: a new approach for right intrahepatic stones. VideoGIE 2019; 4: 420-422

[5] Nakai $Y$, Isayama $\mathrm{H}$, Umefune $\mathrm{G}$ et al. Percutaneous transhepatic cholangioscopyassisted repositioning of misplaced endoscopic ultrasound-guided pancreatic duct stent. Endoscopy 2016; 48 (Suppl. 01): E129-E130

Bibliography

DOI https://doi.org/10.1055/a-1119-0987

Published online: 27.2.2020

Endoscopy 2020; 52: E320-E321

(c) Georg Thieme Verlag KG

Stuttgart - New York

ISSN 0013-726X

\section{ENDOSCOPY E-VIDEOS}

https:|/eref.thieme.de/e-videos

回回 Endoscopy E-Videos is a free access online section, reporting 回: on interesting cases and new techniques in gastroenterological endoscopy. All papers include a high quality video and all contributions are freely accessible online.

This section has its own submission website at https://mc.manuscriptcentral.com/e-videos 